\title{
The Invisible Pandemic: Domestic Violence and Health and Welfare Services in Italy and in the United Kingdom during Covid-19
}

\author{
Aluette Merenda*, Maria Garro, Massimiliano Schirinzi \\ Department of Psychology, Educational Science and Human Movement - University of Palermo, Italy \\ *Corresponding Author: Aluette Merenda, Department of Psychology, Educational Science and Human \\ Movement - University of Palermo. Italy
}

\begin{abstract}
:
Background: International research has shown how Domestic Violence (DV) can escalate during and after or large-scale crises or natural disaster. In many parts of the world, the introduction of lockdown, together with periods of global self-isolation in order to reduce the spread of SARS-CoV-2, has put families, women and children in abusive relationships more at risk, in terms of an "invisible pandemic".

Objective: The purpose of this paper is examining specific reports from Italy and the United Kingdom and analysing how there has been a surge in the pattern of DV cases, recorded globally during the Covid-19 pandemic.
\end{abstract}

Methods: For this purpose, starting from an increased number of DV reports, we examine the typology of Health and Welfare Services, delivered in Italy and in the UK, by a qualitative data collection as a way to show the problematic impact of pandemic measures for those living in and surviving abusive relationships.

Results: Our findings allow a comparison between the two different countries and their Welfare Services, highlighting how lockdown has resulted in a reduction of available support for some families, while many others have experienced significant changes in how this care is provided.

Conclusions: Our discussion and conclusions focus on the challenges posed by Covid-19, as well as on concerns and considerations regarding Governmental policies and Community services between these two countries.

Keywords: Family; Covid-19; Domestic Violence; Welfare Services; Italy; United Kingdom.

\section{INTRODUCTION}

The paper focuses on the potential connection between Domestic Violence (DV) and the impact of pandemic measures on the wellbeing of people, in Italy and in the United Kingdom.

We first examine many types and experiences of Health and Welfare Services during global lockdowns (the first of which was in March 2020, the second in November 2020 and the third is still ongoing), that were adapted to curb the spread of SARS-CoV-2 (the virus that causes the Coronavirus disease 2019 or COVID-19 infection).

It is clear that there has been a surge of DV cases being reported and that a significant pattern is being repeated across the world (Campbell, 2020).

Social restrictions during the pandemic (such as: social distancing, limited travel, the closure of schools, the introduction of home schooling, smart working and shielding), have, in fact, played a significant part in the emotional distress caused to our wellbeing in different ways. This is demonstrated in the higher-than-average requests for help, as well as psychological or medical support (Co-SPACE study 2020; Loades et. al., 2020). 
Although the pandemic has affected all areas of the Health Service in both Italy and the UK, we have chosen to specifically focus on the designated departments for people who are living or who have lived through DV, during the Covid-19 restrictions.

As reported, these measures appear to have contributed to an increased (or to the beginning of a) risk of family violence (or DV) throughout the world, in the form of an intentional use of physical strength or power against another person which results in a high probability of injury, psychological damage and deprivation, or even death (WHO, 2020). And, while no clear precedent for the current crisis exists in academic literature, exploring the impact of natural disasters on DV reports may provide important insights for family violence victims, as well as for professionals helping these victims (NZFVC, 2020).

During the last few years, several studies have shown an increase in familiar disorders and violence during and following large-scale natural disasters such as earthquakes, floods, hurricanes, wars and political persecutions (Almqvist and Brandell-Forsberg, 1997; Fothergill, 2008; Schumacher et al., 2010; Chan and Zhang, 2011; Rezaeian, 2013; Gearhart et al., 2018).

Mak et al. (2010) also confirm this in their Hong Kong study which examines the Severe Acute Respiratory Syndrome that first appeared in China in 2002. They refer to answers given in an interview which revealed the presence of PTSD soon after the spread of the disease, and in some cases, up to 30 months afterwards.

In line with this study, many others have chosen to focus primarily on the possible connection between disease - in terms of epidemics or pandemics - and DV (Ryff and Singer 1998; Schaller and Murray 2008; Mortensen et al., 2010).

The aim of interest here appears to be specifically oriented towards an analysis of chronic levels of negative emotions and DV, linked to the symbolic representation of the disease or, also, of restricted physical activity, emotional distress and different types of addictions (Richman et al., 2005; Vetter et al., 2008; Mortensen et al., 2010).

Merton (1938; 1968), in his exploration of 'sociological ambivalence', explains the abusive dynamics during or after a large-scale crisis. In particular, because communities are governed by standards or norms, he defines them as social patterns, characterised by both a moral and a technical dimension. These patterns are therefore useful in reaching specific aims, which depend on a personal ethical evaluation. With regards to the 2019 pandemic, it is evident that the adhesion to a shared norm, such as lockdown, has offered an opportunity to respect both moral and ethical codes (maintaining social distancing, for instance). Regarding the technical dimension, Dollard pointed out the FrustrationAggression theory (Dollard et al., 1939). As Smithsimon (2018) has also confirmed, this theory explains how devastating the consequences of isolation can be, even if only partially, and how it is impossible for people to live isolated from others.

Similarly, Sprang and Silman (2013), whilst studying psychosocial responses by children and parents to pandemic disasters, emphasise how average scores of PSTD were found to be four times higher in children subjected to quarantine measures than to those who had not.

According to academic literature and the current alarming reports, it is important to bear in mind the complex interplay between DV, family lifestyle (and socioeconomic status) and pandemic measures, highlighted by different ongoing studies (see Co-SPACE study, 2020; Resilience and coping: supporting transitions back to school Report; Talking to children about illness Report; Managing uncertainty in children and young people Report, by Royal College of Pediatrics and Child Health 2020).

As a way of unravelling the meaning of the pandemic measures, in terms of what they represent for those exposed to abusive relationships, we can consider the "pandemic paradox" (Bradbury-Jones and Isham, 2020).

During lockdown, work and family, have been transformed into two strongly interacting worlds. Particularly for DV families, being constantly together in the home, sharing living spaces and new domestic roles, appears to have contributed to different types of violence and dysfunctional behaviours (Morton, 2020). 
Moreover, due to the miscellany of DV forms (Meyersfeld, 2003), any one of these abusive actions could be inflicted on adult victims of DV, but also on children and pets, where there is a risk of suffering significant physical and/or emotional harm (Campbell et. al., 2017; Campbell, 2020; Pfitzner et al., 2020).

From this perspective, the trending slogans during the Covid-19 pandemic ('Stay Safe' and 'Stay Home'), are not always safe recommendations. In fact, for adults and children living in situations of domestic and familial violence, home is often the space where physical, psychological and sexual abuse occurs. This is because home can be a place where dynamics of power are distorted and subverted by those who abuse, often without scrutiny from anyone "outside" the couple, or the family unit (Nancarrow, 2020). This explains why, during the Covid-19 crisis, the advice to 'stay at home' has major implications for those adults and children who are already living with someone who is abusive or controlling (Bonell, 2020).

Similarly, as reported by different resources (articles published in Journals, Newspapers and Governmental reports), there was a continued control of social media by the abusers meaning that the "invisible victims" were hampered in their search for help (Campbell, 2020). In some cases, Covid-19 was also partly responsible for creating fear for these victims, as they were told to continually wash their hands to avoid contracting the infection (Shokair and Hamza, 2020).

In terms of a 'double pandemic', of DV during COVID-19, or an 'invisible pandemic', restrictive measures are therefore likely to play into the hands of people who abuse through tactics of control, surveillance and coercion. In this way, although unintentional, lockdown measures may therefore grant people who abuse greater freedom to act without scrutiny or consequence (Bettinger-Lopez and Bro, 2020).

\section{METHODS}

Starting a systematic search of PsychINFO, CINAHL Web of Science and PubMed, our qualitative analysis began from an increasing rates of DV around the world.

During lockdowns, DV reports have in fact increased in several countries. For instance, in China and in the US it is reported DV has tripled. Additionally, in the UK, lots of Violence Helplines increased their calls, after the announcement of lockdown measures (BMJ, 2020). Similarly, in Italy, from March to June 2020, the number of requests for help doubled (+119\%), compared to the same period in 2019 (FishOnlus,2020).

At the same time, and in contrast to increasing reports of DV, many Child Welfare organisations have noticed a significant drop in reports of child abuse. This decrease may be the result of fewer opportunities for detection (for instance, by the closure of schools), as opposed to an actual decrease in incidence (Campbell, 2020) and a limited number of key community partners in their ability to report abuse (Shokair and Hamza, 2020; Jagannathan, 2020).

Besides, the increased number of new DV cases (that rose by $1493 \%$ after lockdown, as mentioned by BMJ, 2020), highlights also the risk of intergenerational transmission. The current outbreak of violence, in fact, not only may have an impact on the wellbeing of who affected now, but also on their future health and wellbeing and those of their children (Roseboom, 2020; 369: $\mathrm{m}$ 2327).

\section{FINDINGS}

A comparative study between Italy and the UK, regarding the impact of the pandemic on DV, is reported below. Due to the complexity of the ongoing situation, our data collection is limited because there is no specific statistical data or systematic indicators to evidence a reliable comparison on the trend, both quantitatively and qualitatively, of the problem in the two nations. Nevertheless, a short overview of the findings allows a comparison between the two different countries and their Welfare Services.

In Italy. The Italian Health National Service (INHS, 1978), is a public service mainly funded by general taxation that provides universal coverage and comprehensive healthcare (http://www.salute. gov.it). Unlike the NHS in the UK, the Italian system is highly decentralised and the 20 regions of the country are each legally responsible for planning services and allocating financial health resources 
(Del Vecchio, De Pietro, 2011). This local autonomy implies financial accountability, which allows regions to develop substantially different health strategies without national endorsement. It is a common view among experts that Italy has 20 NHSs, and that in reality, a national policy is not necessarily applied by all regions homogeneously (European Observatory on Health Care Systems. Health Care Systems in Transition-Italy. WHO Regional Office for Europe, Copenhagen, 2001). Accident and emergency services (AEs) are the 'pillar' of emergency care in the INHS, as they are in the NHS in the UK. The crucial issue for Italian AEs is that they are located in many public hospitals that are of a small size (around 30\% with less 120 beds, and only 15\% with more than 600 beds). Many efforts to make public hospital networks more rational have failed, eventually leading to questionable re-organisation at a local level (Del Vecchio, De Pietro, 2011).

The typology of Health and Welfare services, as a way to support Italian people affected by Covid-19 restrictions and especially those families and DV victims, is described below:

The campaign Libera puoi, which was introduced on the $23^{\text {rd }}$ March 2020 and sponsored by the Italian Government, promoted the 1522 anti-violence hotline, for those forced to stay home with a violent partner during lockdown (see http://www.governo.it/it/media/campagna-di-comunicazionelibera-puoi/14459).

Specifically, Lombardia was the Italian region which received the largest number of requests for help (990, during the first lockdown) for confirmed violence. In most cases, the victims were women (6254 women and $253 \mathrm{men}$ ), and were not only at the hand of a partner or ex-partner (see http://www.governo.it/it/media/campagna-di-comunicazione-libera-puoi/14459, published 15th April 2020).

But already before this pandemic, in Italy our data collection highlights a surge in DV: in 2019, 2251 Italians phoned 1522 to report violence. In 2020, the number was 5016. To be more specific, 2285 reported psychological violence (1100 in 2019) and 277 reported sexual violence (127 in 2019) (Fish Onlus, 2020, see: https://www.fishonlus.it/2020/11/25/fish-no-alla-violenza-sulle-donne-no-alladiscriminazione).

During lockdown, the hotline provided information and advice. The implementation of another app, YouPol from State Police, was another useful instrument in managing requests for help for victims of violence. This app was created to help with bullying and drug dealing in schools, but it has now been updated to help fighting DV too (see: https://www.poliziadistato.it/articolo/135e74a0112e9af8588 4805/YouPolApp).

Besides, Anti-Violence centres tried to be at the heart of the local network to take on female victims of violence. Referring to the Geneve Convention (2011) against violence towards women (then ratified in Italy in 2013), the International Committee of the Red Cross (ICRC) works in close coordination with Authorities and Anti-violence centres to understand what type of protective measures should be used to prevent the spread of Covid-19.

They therefore work as an international instrument to create a complete regulatory framework to protect people and families from any violence (https://www.icrc.org/en/what-we-do/covid-19pandemic).

The Italian Ministry for Equal Opportunity supported the financing of urgent measures to support anti-violence centres and refugees. (pariopportunita.gov.it).

Below, here are two projects run in Italy by Terre des Hommes:

Consultami - Spazio Indifesa (https://consultami.org/, started in October 2020) and Network Indifesa Empowerment Ragazze (https://www.campagna-di-terre-des-hommes-indifesa-spot/, started in September 2019), as two services in support of women and young female victims of physical, psychological or economic violence.

ActionAid called for help, which works in the large and small Italian towns, reporting the failure of medical devices (face masks, hand sanitizer, gloves) (see: https://www.actionaid.it/).

But, in spite of these actions and projects delivered during the pandemic, the reception of victims of DV has been reduced. Indeed, unless in an emergency, those people (especially women and children), 
although forced away from their homes, have had their requests for help denied. The main reason of that is explained by the fact that those women who did not contact Anti-Violence centres before Covid-19, have seen a reduction in access. In the aftermath, due to social distancing restriction, as an additional obstacle for these services to be easily accessed by victims, the reception has diminished even further.

In the UK. The UK Government announced (on the $23^{\text {rd }}$ March 2020) that people who are classed as 'vulnerable' (or 'clinically extremely vulnerable') due to additional underlying health conditions (such as: shielding people or people affected by autism, dementia, anxiety, depression, self-harm, eating disorders and so on; see Royal College of Paediatrics and Child Health 2020) should take extra precautions, if they are exposed to Covid-19 restrictions (https://www.gov.uk/government/ publications/guidance-on-shielding-and-protecting-extremely-vulnerable-persons-from-covid-19).

Similarly, for those people impacted over the lockdown and experiencing DV, more studies are focusing their attention on how to keep safe during this uncertain period (Loades et al., 2020), as top priority. In particular, children are considered more in danger than others, falling through the safety net, due to a reduced access to support services and fewer opportunities for people outside the family to sound the alarm (https://www.scie.org.uk/care-providers/coronavirus-covid-19; Sidpra et al. 2020).

In accordance with this concern, as anyone can be at risk of contracting Covid-19 and be a victim of domestic abuse (regardless of health-physical, gender, age, ethnicity, socio-economic status, sexuality or background), a list of the main organisations to get support from, was published on line (https://www.scie.org.uk/care-providers/coronavirus-covid-19/safeguarding/domestic-violence-abuse).

Specifically, a list of main links for websites and organisations providing relevant information and educational, legal and psychological support is attached below (https://www.scie.org.uk/children):

Services for victims of domestic abuse: Refuge's National Domestic Abuse Helpline for free support (24 hours a day), for an immediate risk of harm to someone, or as an emergency;

Sexual assault referral centres (SARCs): a medical and emotional support for anyone (adults and children), who has been raped or sexually assaulted. They provide advice in a safe environment and have specially trained doctors, nurses and support workers;

Specialist services for children and young people: for anyone with concerns about a child or teens. In particular, there is a specialist service for Adolescent to parent violence (APV), when the DV covers abuse between family members, such as adolescent to parent violence and abuse, they can receive a support, raising children who aren't able to live with their parents;

Specialist services for people from ethnic minorities: for Latin American women suffering from domestic abuse, support for Middle Eastern, North African and Afghan women and girls living in the UK, suffering from domestic abuse, forced marriage, FGM and honour-based abuse; women's organisation addressing violence against black and minority women and girls; advocacy and information for Asian and Afro-Caribbean women suffering abuse;

Specialist services for people with disabilities: domestic abuse support for deaf people in British Sign Language (BSL) and disabled victims and survivors of abuse;

Specialist services for an abuser: an anonymous and confidential helpline for men and women, who are harming their partners and families. The helpline also takes calls from partners or ex-partners, friends and relatives who are concerned about perpetrators.

Services for professionals: for employers, if they are facing domestic abuse. Or for professionals who may also be worried about their own abusive behaviour at this time.

In conclusion, in spite of several types of Health Services, they have been delivered and experienced differently by people. Indeed, for some, lockdown has resulted in a reduction of available support, while many others have experienced significant changes in how this care is provided. This includes social isolation and loneliness, reduced contact with loved ones and carers, lack of access to routine activities, and an associated increased distress which may show itself as anger, frustration, anxiety, sadness, grief and so on (see Guidance for Health Professionals supporting groups with specific complex needs; https://www.bps.org.uk/coronavirus-resources/professional/effective-public-healthcampaigns). 
In accordance with Guidance perspective (see Guidance for Health Professionals supporting groups with specific complex needs, published by British Psychological Society, 2020; Parker, 2020; https://www.bps.org.uk/news-and-policy/new-guidance-published-support;

https://www.bps.org.uk/coronavirus-resources/professional; https://www.bps.org.uk/coronavirus-reso urces/ professional/effective-public-health-campaigns), people who are experiencing DV or are considered vulnerable, are likely to exhibit an increased dependency on other people for care and support in their day-to-day lives (Hysing et al. 2007). And this is, moreover, the main reason for which the British Psychological Society (BPS, 2020) has published six new guidance documents (as road maps) to help Health professionals encourage people to adopt healthy behaviours, during the pandemic (which, at the moment, is in its third wave).

In particular, these documents focus on the following topics (https://www.bps.org.uk/news-andpolicy/new-guidance-published-support-intimate-relationships-during-lockdowns; https://www.bps.org.uk/coronavirus-resources/professional; Crosby et al. 2020):

Alcohol consumption. To support health officials to consider changes to alcohol consumption occurred during the Covid-19 pandemic and to use psychologically-informed behaviour change approaches to optimise health improvement and mitigate increases in alcohol use.

Eating behaviour. To support health officials to consider changes to eating behaviour that may have occurred during the Covid-19 pandemic and to use psychologically-informed behaviour change approaches to optimise health improvement and mitigate negative eating patterns.

Physical activity. To support health officials to consider changes to physical activity that may have occurred during the Covid-19 pandemic and to use psychologically-informed behaviour change approaches to optimise health improvement and mitigate a reduction in activity levels.

Sedentary behaviour. To support health officials to consider changes to sedentary behaviour that may have occurred during the Covid-19 pandemic and to use psychologically-informed behaviour change approaches to optimise health improvement and mitigate an increase in time spent sitting or lying down.

Sleep hygiene. To support health officials to consider changes to sleep that may have occurred during the Covid-19 pandemic and to use psychologically-informed behaviour change approaches to optimise health improvement and mitigate a negative change in level and quality of sleep.

Stopping smoking. To support health officials to consider changes to tobacco smoking that may have occurred during the COVID-19 pandemic and to use psychologically-informed behaviour change approaches to optimise health improvement and encourage stopping smoking.

\section{DISCUSSION}

The manuscript highlights how the surge in DV cases may represent a pattern being repeated globally, during the Covid-19 pandemic.

Although, due to the complexity of the ongoing situation, our data collection remains limited to current data resources, our overview of the findings shows a comparison between two different countries and their Health and Welfare Services, that could help the transferability of the findings to other communities and populations.

Specifically reporting from Italy and the United Kingdom, this comparison has shown how DV, as well as sexual and interpersonal violence, can escalate during and after large-scale disasters or crises (Almqvist and Brandell-Forsberg, 1997; Vetter et al., 2008; Schumacher et al., 2010; Mak et al., 2010; Chan and Zhang 2011; Rezaeian, 2013; Sprang and Silman, 2013; Gearhart et al., 2018; Campbell 2020).

Although the DV miscellany of harms, that may explain how its detection still remains a problem to be solved (Meyersfeld, 2003), we can affirm regard both the Italian and British communities, most of their DV services are currently not particularly efficient, due to the higher number of help requests and the lack of victim-serving professionals.

Particularly in Italy, there is an urgency to empower more networks to promptly and successfully support DV victims, even after the actual emergency. 
However, we recognise also a need for communities to be more aware of DV, and how this remains a priority in both countries (Bettinger-Lopez et al.,2020).

We can summarize this issue, as a way to be more aware of the increased health risk of people, and their cares, with abuse experience, focusing on the following levels of intervention, as already published by BPS (BPS 2020/https://www.bps.org.uk/coronavirus-resources/professional/effectivepublic-health-campaigns; Legido-Quigley et al. 2020):

Individual level: a person-centred approach, delivering individualised health advices, rather than generic advice. This could be a way to create new opportunities for engagement people with activities or new interests, or providing health services after lockdown (https://www.bps.org.uk/coronavirusresources/professional/effective-public-health-campaigns).

Service and Systems level: support for people to come out of lockdown, offering different methods of enabling access services and delivering care (such us: both face-to-face and remote working) (https://www.bps.org.uk/coronavirus-resources/professional/effective-public-health-campaigns).

Community level: working with communities to understand the challenges faced by some individuals, in adhering to current safety measures, as a way to raise awareness about hidden risks. (https://www. bps.org.uk/coronavirus-resources/professional/effective-public-health-campaigns).

Moreover, regard the implications of the findings of this study for policy and practice, our report highlights how guidance has been less clear-cut, resulting in confusing messages which are particularly challenging for those with additional communication or special needs (BMJ, 2020). For instance, policies such as: poverty-creating universal credit, reductions in benefit payments and so on, have had strong consequences and need to be urgently reviewed and reversed in both countries (Bonell et al., 2020).

Following this perspective, there is another implication regarding Health professionals: distancing and withdrawal of those who work to assist children and families (such as: early years workers, teachers, youth workers, social workers), are leaving vulnerable people stranded without help (see New LGA analysis on children's social care overspend 2020). And this issue may have a heavy impact of what has been in terms of training for many years. For example, in England, the number of health visitors was reduced by a third between 2015 and 2019, and Government funding for family centres and youth services was cut by more than half from 2010 to 2018, with the Local Government Associations expressing concern that children had disappeared from view (Simpson, 2020; see New LGA analysis on children's social care overspend 2020).

\section{CONClusions}

In conclusion, in both countries and around the world, despite lockdowns, restrictions and other Government advices will continue to change rapidly over the coming months so the current situation appears and remains very challenging (Legido-Quigley 2020). And, as mentioned, this uncertainty and the changing situation have the potential to increase anxiety and psychological distress, both for the individuals themselves and for those who support them (Verity 2020).

We can conclude that it is difficult to fully demonstrate why violence has recently suddenly increased in Italy as in the UK, because there is no specific statistical data or systematic indicators to show a reliable comparison on the trend of the problem in the two nations.

But, both Italy and the UK show alarming data when we take into account that many victims have been unable to report abuse, due to a constant threat of their abusers and the fact they are at home, together with no access to private spaces. And, in terms of what could be called an "invisible pandemic", it is clear that many victims have struggled to access services and that this, in turn, has slowed down their escape paths from violence.

We can affirm then across the world, it would be useful to take a proactive approach to understanding people's needs, incorporating the values of positive behaviour support, where appropriate and necessary, but starting from their experiences of Welfare and Health Services (Branco, 2020). 
The Invisible Pandemic: Domestic Violence and Health and Welfare Services in Italy and in the United Kingdom during Covid-19

As clinicians or researchers we may work to mitigate the current emergency, but a collective effort should be encouraged as well as to ensure many safeguards, not only for DV but in order to alleviate any long-term psychological consequences.

\section{REFERENCES}

Almqvist, K. \& Brandell-Forsberg, M. (1997). Refugee Children in Sweden: Posttraumatic Stress Disorder in Iranian Preschool Children Exposed to Organized Violence. Child Abuse \& Neglect, 21(4), 351-366.

Bettinger-Lopez, C. \& Bro, A. (2020). A Double Pandemic: Domestic Violence in the Age of COVID-19. Retrieved from_https://www.cfr.org/in-brief/double-pandemic-domestic-violence-age-covid-19.

BMJ. (2020). Surge in domestic child abuse during pandemic, reports specialist UK children's hospital: Rise of 1493 percent in one month compared with same period in previous three years. Science Daily. Retrieved from www.sciencedaily.com/releases/2020/07/200702192119.htm.

Bonell, C., Michie, S., Reicher, S., West, R., Bear, L., Yardley, L., Curtis, V., Amlôt, R., \& Rubin, G. J. (2020). Harnessing behavioural science in public health campaigns to maintain 'social distancing' in response to the COVID-19 pandemic: key principles. Journal of Epidemiology and Community Health, 74:617-619. https://dx.doi.org/10.1136/jech-2020-214290.

Bradbury- Jones, C., \& Isham, L. (2020). The pandemic paradox: The consequences of COVID- 19 on domestic violence. Journal of Clinical Nursing, 29, 2047-2049. doi:10.1111/jocn.15296.

Branco, P. (2020). Disaster and emergency preparedness and response. Retrieved from https://vawnet.org/sc/ disaster-and-emergencypreparedness-and-response.

Campbell, A. M., Hicks, R. A., Thompson S. \& Wiehe, S. (2017). "Characteristics of Intimate Partner Violence incidents and the environments in which they occur: Victim reports to responding law enforcement officers". Journal of Interpersonal Violence. Retrieved fromhttp://journals.sagepub.com/doi/ abs/10.1177/0886260517704230.

Campbell, A.M. (2020). An increasing risk of family violence during the Covid-19 pandemic: Strengthening community collaborations to save lives. Forensic Science International: Reports, (2) 100089. https://doi.org/10.1016/j.fsir.2020.100089.

Chan, K. L., \& Zhang, Y. (2011). Female victimization and intimate partner violence after the May 12, 2008, Sichuan earthquake. Violence and victims, 26(3), 364-376. https://doi.org/10.1891/0886-6708.26.3.364

Crosby, L., McCloud,T., Hudson, L., Nicholls, D., De Stavola, B., Fowler,D., Viner, R., \& Patalay, P. (2020). Disruptions experienced by young people aged 16-24 during first months of the COVID-19 lockdown. Retrieved from https://www.ucl.ac.uk/child-health/research/population-policy-and-practice-research-andteaching-department/covid-19-studies/you-cope.

Curtis, L., \& Burns, A. (2016). Unit Costs of Health and Social Care 2016', Personal Social Services Research Unit. Retrieved from: https://www.pssru.ac.uk/project-pages/unit-costs/unit-costs-2016/

Del Vecchio, M. \& De Pietro, C. (2011). Italian Public Health Care Organizations: Specialization, Institutional Deintegration, and Public Networks Relationships. International Journal of Health Services. https://doi.org/10.2190/HS.41.4.i.

European Observatory on Health Care Systems. Health Care Systems in Transition-Italy. WHO Regional Office for Europe, Copenhagen, 2001. Google Scholar.

Dollard, J., Doob, L. W., Miller, N. E., Mowrer, O. H. \& Sears, R. R. (1939). Frustration and Aggression. New Haven, CT: Yale University Press.

Fish Onlus (2020). No alla violenza sulle donne, No alla discriminazione. https://www.fishonlus.it/2020/ 11/25/fish-no-alla-violenza-sulle-donne-no-alla-discriminazione/).

Fothergill, A. (2008). Domestic Violence after Disaster: Voices from the 1997 Grand Forks Flood. In B. D. Phillips and B. H. Morrow (Eds.), Women and Disasters: From theory to practice (pp131-154). USA: International Research Committee on Disasters.

Gearhart, S., Perez-Patron, M., Hammond, T. A., Goldberg, D. W., Klein, A., \& Horney, J. A. (2018). The impact of natural disasters on domestic violence: An analysis of reports of simple assault in Florida (19992007). Violence and Gender, 5(2), 87-92.https://doi.org/10.1089/vio.2017.0077.

Hysing, M., Elgen, I., Gillberg, C., Lie, S.A., \& Lundervold, A.J. (2007). Chronic physical illness and mental health in children. Results from a large-scale population study. Journal of Child Psychology and Psychiatry, 48(8), 785-792. doi: 10.1111/j.1469-7610.2007.01755.x.

Jagannathan, M. (2020, November 23). 'We've seen an alarming spike in domestic violence reports:' For some women, it's not safe to leave the house OR stay home. Retrieved from https://www.marketwatch.com.

Legido-Quigley,H, Asgari, N, Teo, YY, Leung, GM, Oshitani, H, Fukuda, K, Cook, AR, Hsu, LY, Shibuya, K., \& Heymann, D. (2020). Are high-performing health systems resilient against the COVID-19 epidemic? Lancet, 395(10227),848-850. doi: 10.1016/S0140-6736(20)30551-1. 
Loades, M.E., Chatburn, E., Higson-Sweeney, N., Reynolds, S., Shafran, R., Brigden, A., Linney, C., McManus, M.N., Borwick, C., \& Crawley, E. (2020). Rapid systematic review: The impact of social isolation and loneliness on the mental health of children and adolescents in the context of COVID-19. Journal of the American Academy of Child \& Adolescent Psychiatry, 59(11), 1218-1239.e3. doi.org/10.1016/ j.jaac.2020.05.009.

Mak, IWC., Chu, CM., Pan, PC., Yiu, MGC., Ho, SC., \& Chan, VL. (2010). Risk factors for chronic posttraumatic stress disorder (PTSD) in SARS survivors. General Hospital Psychiatry,32(6), 590-598. DOI:10.1016/j.genhosppsych.2010.07.007.

Merton, R. K. (1938). Social Structure and Anomie. American Sociological Review,3(5), 672-682. Retrieved from http://www.jstor.org/stable/2084686. Merton, R. (1968). Social Theory and Social Structure. New York: The Free Press.

Meyersfeld, B. (2003). "Reconceptualizing Domestic Violence in International Law". Albany law review, 67, 371.

Mortensen, C.R., Becker, D.V., Ackerman, J.M., Neuberg, S.L., \& Kenrick, D.T. (2010). Infection breeds reticence: The effects of disease salience on self-perceptions of personality and behavioral avoidance tendencies. Psychological Science, 21, 440-447. doi: 10.1177/0956797610361706.

Morton, R. (2020, October). Family violence increasing during Covid-19 lockdown. The Saturday Paper, 4 April. Retrieved from https:// www.thesaturdaypaper.com.au/news/law-crime/2020/04/04/family-violenceincreasing-during-covid-19- lockdown/15859188009641.

Nancarrow, H. (2019), Unintended Consequences of Domestic Violence Law. Gendered Aspirations and Racialised Realities, Hoepli.

New Zealand Family Violence Clearinghouse.(2020). Family violence and sexual violence service provider update MSD, COVID response funding. Retrieved from https://nzfvc.org.nz/news/family-violence-andsexual-violence-service-provider-update-msd-nov-2020-covid-response-funding.

New LGA analysis on children's social care overspend (2020). ADCS. Retrieved from https://adcs.org.uk/funding/article/new-lga-analysis-on-childrens-social-care-overspend.

Parker, J. (2020). Social Worker Practice (6 ${ }^{\text {th }}$ edition). Learning Matters. London: Sage.

Pascual-Sanchez, A., Nicholls, D., Patalay, P., Crosby, L., McCloud, T., Hudson, L., De Stavola, B., Fowler, D., \& Viner, R. (2020). You-COPE. Mental health consequences experienced by young people aged 16-24 during first months of the COVID-19 lockdown. Retrieved from https://www.ucl.ac.uk/childhealth/research/population-policy-and-practice-research-and-teaching-department/covid-19-studies/youcope.

Pfitzner, N., Fitz-Gibbon, K., \& True, J. (2020). Responding to the 'Shadow Pandemic': Practitioner views on the nature of and responses to violence against women in Victoria, Australia during the COVID-19 restrictions. Monash University Report. https://doi.org/10.26180/5ed9d5198497c.

Rezaeian, M. (2013).The association between natural disasters and violence: A systematic review of the literature and a call for more epidemiological studies. Journal of Research in Medical Sciences, 18(12):1103-1107.

Richman, L. S., Kubzansky, L., Maselko, J., Kawachi, I., Choo, P., \& Bauer, M. (2005). Positive Emotion and Health: Going Beyond the Negative. Health Psychology, 24(4), 422-429. https://doi.org/10.1037/02786133.24.4.422.

Roseboom, T.J. (2020). Violence against women in the covid-19 pandemic: we need upstream approaches to break the intergenerational cycle. BMJ 2020; 369 doi: https://doi.org/10.1136/bmj.m2327.

Royal College of Paediatrics and Child Health. (2020). COVID-19 - 'shielding' guidance for children and young people. Retrieved from www.rcpch.ac.uk/resources/covid-19-shielding-guidance-children-young-people.

Ryff, C. D., \& Singer, B. (1998). The contours of positive human health. Psychological Inquiry, 9, 1-28. doi.org/10.1207/s15327965pli0901_1.

Schaller, M., \& Murray, D.R. (2008). Pathogens, Personality, and Culture: Disease Prevalence Predicts Worldwide Variability in Sociosexuality, Extraversion, and Openness to Experience. Journal of Personality and Social Psychology, 95, 212-221. DOI: 10.1037/0022-3514.95.1.212.

Schumacher, JA., Coffey, SF., Norris, FH., Tracy, M., Clements, K., \& Galea, S. (2010). Intimate partner violence and hurricane Katrina: Predictors and associated mental health outcomes. Violence and Victims, 25(5):588-603.

Shokair, Z.\& Abo Hamza, E. (2020). Family Violence and its Impact on Children's Mental Health During COVID-19 Pandemic. International Journal of Instructional Technology and Educational Studies, 1(3), 32-39. doi: 10.21608/ihites.2020.42946.1035. 
The Invisible Pandemic: Domestic Violence and Health and Welfare Services in Italy and in the United Kingdom during Covid-19

Sidpra, J., Abomeli, D., Hameed, B., Baker, J. \& Mankad, K. (2020). Rise in the incidence of abusive head trauma during the COVID-19 pandemic. Archives of Disease in Childhood, archdischild-2020-319872 DOI: 10.1136/archdischild-2020-319872.

Simpson, F. (2020, November 19). DCS turnover at highest level for a single quarter. Children and Young people now, https://www.cypnow.co.uk/news/article/dcs-turnover-at-highest-level-for-a-single-quarter.

Smithsimon, G. (2018). Cause: and how it does not always equal effect. Melville House Publishing.

Sprang, G., \& Silman, M. (2013). Posttraumatic stress disorder in parents and youth after health- related disasters. Disaster Med Public Health Prep, 7: 105-10. DOI:10.1017/dmp.2013.22.

Verity, R., Okell, L.C., Dorigatti, I., Winskill, P., Whittaker, C., Imai, N., Cuomo-Dannenburg, G., Thompson, H., Walker, P. G. T., Fu, H., Dighe, A., Griffin, J. T., Baguelin, M., Bhatia, S., Boonyasiri, A. , Cori, A., Cucunubá, Z., FitzJohn, R., Gaythorpe, K., Green, W., Hamlet, A., Hinsley, W., Laydon, D., NedjatiGilani, G., Riley, S., van Elsland, S., Volz, E., Wang, H., Wang Y., Xi, X., Donnelly, C. A., Ghani, A.C., \& Ferguson, N. M (2020). Estimates of the severity of coronavirus disease 2019: a model-based analysis. Lancet Infectious Disease March 30. Retrieved from https://doiorg/101016/S1473-3099(20)30243-7 20202.

Vetter, S., Rossegger, A., Rossler, W., Bisson, J. I., \& Endrass, J. (2008). Exposure to the tsunami disaster, PTSD symptoms and increased substance use. An Internet based survey of male and female residents of Switzerland. BMC Public Health, 8, 92. doi.org/10.1186/1471-2458-8-92.

WHO (2020) Definition and typology of violence. Available at: https://www.who.int/violenceprevention/ approach/definition/en/.

Wilcox, P. (2012). Is parent abuse a form of domestic violence? Social Policy and Society, 11(02):277-288. Cambridge University Press. https://doi.org/:10.1017/S1474746411000613.

Citation: Aluette Merenda et al. "The Invisible Pandemic: Domestic Violence and Health and Welfare Services in Italy and in the United Kingdom during Covid-19" International Journal of Humanities Social Sciences and Education (IJHSSE), vol 8, no. 10, 2021, pp. 11-20. doi: https://doi.org/10.20431/23490381.0810003 .

Copyright: (C) 2021 Authors. This is an open-access article distributed under the terms of the Creative Commons Attribution License, which permits unrestricted use, distribution, and reproduction in any medium, provided the original author and source are credited. 